\title{
Floral morphology and structure of Emblingia calceoliflora (Emblingiaceae, Brassicales): questions and answers
}

\author{
Hiroshi Tobe
}

Received: 24 November 2014 / Accepted: 8 January 2015 / Published online: 11 February 2015

(C) The Botanical Society of Japan and Springer Japan 2015

\begin{abstract}
Emblingia calceoliflora, the sole species of the family Emblingiaceae (Brassicales), is a creeping shrub endemic to South Western Australia. The flowers have a characteristic slipper-like corolla (calceolus). Earlier studies using dry specimens have left some questions regarding the flower unresolved. Here I present an anatomical study of fresh flowers to resolve these questions. The flowers are pedicellate, strongly monosymmetric, and pentamerous with the median sepal in the abaxial position. During flower development, a pedicel turns clockwise or anticlockwise, placing the adaxial calceolus (comprising both petals) downward and a transversely dilated androgynophore upward with a large tunnel-like space between them. Two short longitudinal walls develop from the basal part of the petals, enclosing a nectary gland deep in the flower. The vascular anatomy of the androgynophore shows that lateral dédoublement occurs in five stamens, resulting in two pairs of fertile stamens on the adaxial side and (three to) six staminodes as the "hood" on the opposite side. Androecial configuration is obhaplostemony, and the gynoecium is tricarpellate/trilocular. Comparisons with flowers of other Brassicales show that an extrastaminal nectary is a synapomorphy of the core Brassicales including Emblingiaceae. The flower of Emblingia is highly specialized for adaptation to insect-pollination.
\end{abstract}

Keywords Brassicales - Emblingia - Emblingiaceae · Floral anatomy $\cdot$ Floral morphology $\cdot$ Flowers

H. Tobe $(\bowtie)$

Department of Botany, Graduate School of Sciences,

Kyoto University, Kyoto 606-8502, Japan

e-mail: tobe@sys.bot.kyoto-u.ac.jp

\section{Introduction}

Emblingia calceoliflora $\mathrm{F}$. Muell. is a subshrub with shoots creeping on the sandy soil in the Irwin district of Western Australia (Fig. 1a, b). The species had been placed in various families such as Capparaceae or Capparidaceae (Mueller 1860-1861; Bentham and Hooker 1862-1867; Diels and Pritzel 1905; Pax and Hoffmann 1936; Melchior 1964), Polygalaceae (Cronquist 1981), or Sapindaceae (Thorne 1992); or its own family Emblingiaceae (Airy Shaw 1965; Dahlgren 1980; Takhtajan 1980). However, with the accumulation of molecular evidence (Chandler and Bayer 2000), the Angiosperm Phylogeny Group (APG 1998; APGII 2003; APGIII 2009) has consistently accepted the monogeneric family Emblingiaceae in the order Brassicales. Within Brassicales, Emblingiaceae are sister to the rest (eight families) of the core Brassicales (Hall et al. 2004; Su et al. 2012; for phylogenetic relationships of Emblingiaceae in the Brassicales see Fig. 5).

Emblingia calceoliflora and its reproductive morphology were first described more than 150 years ago with some line drawings of shoots, flowers, and fruits (Mueller 1860-1861). In short, the flowers are monosymmetric; the calyx divides itself into five lobes with a longitudinal slit on the anterior side; the corolla comprises two petals, which are valvate and connate to form a characteristic "calceolus" (slipper-like corolla); an androgynophore (torus) with four stamens and four or five appendages is on the top and a swollen nectary gland is at the base (Fig. 1c); and the ovary is trilocular with a single ovule per locule. Mueller (1860-1861), however, did not refer to positional relationships among the sepals, petals, stamens, and carpels. Some 100 years later, three experts (G. Erdtman, P. Leins and R. Melville) reinvestigated floral morphology and structure of the species using herbarium specimens (Erdtman 


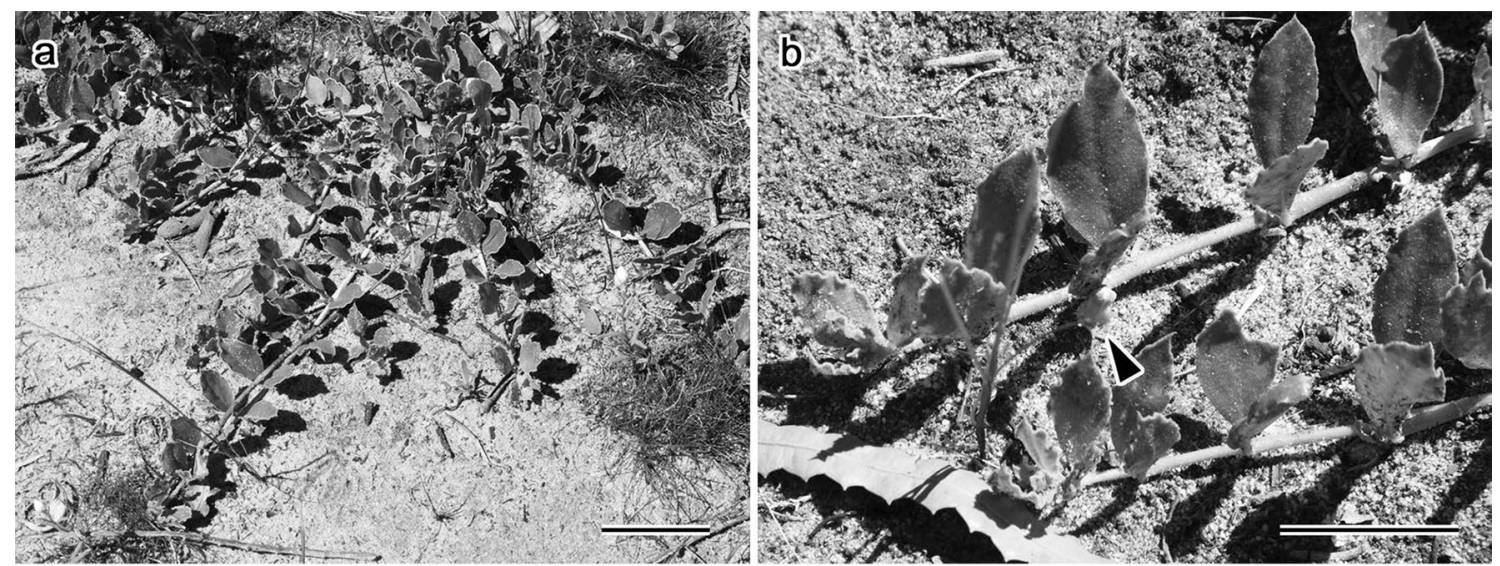

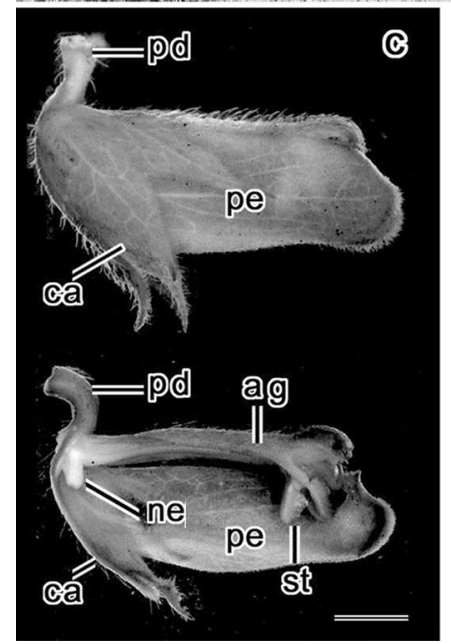

d

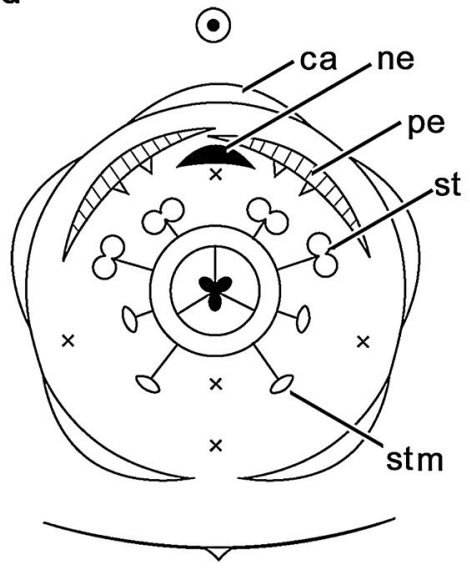

e

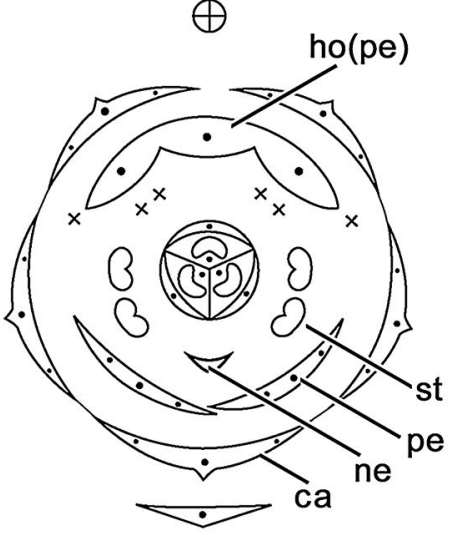

Fig. 1 Emblingia calceoliflora. a, b The plant growing in its natural habitat in Western Australia. Note the creeping shoots with opposite leaves and solitary flowers (arrowhead) from the leaf axils. c Two flowers at anthesis, viewed from the lateral side. One petal and two sepals were removed from the flower at the lower side. Note that the petals (calceolus) are positioned downward in the field, and that the flowers have a short pedicel which turns to different directions. d, e
Floral diagrams redrawn from Leins and Melville in Erdtman et al. (1969). Note the differences in floral orientation and the number and positions of petals and stamens. $a g$ androgynophore, ca calyx, ho (pe) hood (interpreted as having developed from the petals), $n e$ nectary, $p e$ petal, st stamen, stm staminode. Scale bars are $10 \mathrm{~cm}$ in $\mathbf{a}, 5 \mathrm{~cm}$ in $\mathbf{b}$, and $2 \mathrm{~mm}$ in $\mathbf{c}$

on the anterior side (where the androgynophore is also present). However, it was uncertain whether the deep calyxslit was positioned on the adaxial side or abaxial side. Erdtman and Melville concluded that the flower has an adaxial androgynophore and an abaxial calceolus, whereas Leins considered the androgynophore to be abaxial and the calceolus to be adaxial (Fig. 1d, e; see floral diagrams in Erdtman et al. 1969, pp. 173, 177). In more recent publications, Watson and Dallwitz (1992 onwards) and Takhtajan (1997, 2009) adopted Lein's interpretation, and Stevens (2001 onwards) adopted Melville's interpretation. Stevens (2001 onwards) questioned whether the flower is resupinate or not. Our question is where the calceolus is exactly positioned in relation to the flower-bearing axis.

Second, how are petals positioned in a flower? Both Leins and Melville agreed that the flower originally had five petals, two of which form the calceolus. Leins further 
interpreted that the three remaining petals have been lost. In contrast, Melville interpreted that of the three remaining petals, two were lost and one developed into a trinerved hood (leafy appendage on the androgynophore). Our question is which interpretation is correct, Leins' or Melville's? Or, is perhaps another interpretation possible?

Third, how many stamens were originally present in a flower? Although Mueller (1860-1861) described the flower as having four free fertile stamens, both Leins and Melville considered that the flower originally had more numerous stamens (Erdtman et al. 1969). According to Leins, ten stamens originally existed in two whorls of five stamens; of these ten stamens, the adaxial and abaxial stamens were lost, four latero-adaxial stamens were fertile, and four latero-abaxial stamens were sterile to form the "hood." In contrast, Melville assumed that five stamens were originally present in a flower. Of these five stamens, two latero-abaxial ones are fertile, each dividing into two: thus, a total of four stamens being visible, two latero-adaxial stamens being lost, and the abaxial stamen developed into a nectary gland. Besides the number of stamens, the question thus arises, whether any stamen(s) developed into the hood or the nectary?

Finally, how many carpels constitute a gynoecium? Mueller (1860-1861) described the gynoecium as uniovulate and unilocular, whereas both Leins and Melville agree that the gynoecium is tricarpellate with an ovule in each locule (Erdtman et al. 1969). Takhtajan (1997, 2009) and Stevens (2001 onwards) described the gynoecium as having two or three carpels, with the ovary being bi- to trilocular and with one basal ovule in each locule. Melchior (1964) and Watson and Dallwitz (1992 onwards) described the gynoecium as unicarpellate and unilocular. We have to confirm whether the gynoecium is unicarpellate or tricarpellate, and how each ovule is attached to the placenta.

As stated above, previous studies on Emblingia flowers have left uncertainty regarding the following aspects: (1) the flower orientation in relation to the flower-bearing axis, (2) the number and positions of fertile or missing petals and stamens, (3) the number of carpels, and (4) the origin of the nectary gland and hood. Answers to these questions will provide an understanding of the exact floral structure of Emblingia. Emblingia is no longer closely related to Sapindaceae, as Leins suggested, and nor even to Goodeniaceae, as Melville suggested (see Erdtman et al. 1969). Its flowers must be compared to those of the Brassicales, particularly with those of the core Brassicales.

The purpose of the present study is primarily to clarify the exact structure of the flowers of Emblingia to answer the aforementioned questions. I collected ample fresh flowers including young buds in the field in Western Australia. I recently published floral anatomical studies of Cardiopteris (Cardiopteridaceae) (Tobe 2012), Phyllonoma
(Phyllonomaceae) (Tobe 2013), and Helwingia (Helwingiaceae) (Ao and Tobe 2015). They contributed to a better understanding of how the flowers of individual taxa are characterized in an evolutionary context. Here, I present an anatomical study of Emblingia flowers. Ronse de Craene and Haston (2006) discussed the evolution of morphological characters in the Brassicales including Emblingiaceae in a combined morphological-molecular study. Regarding the flowers, a total of 42 characters were used for their analyses. Among them, data for 36 characters were obtained for Emblingia based on previously published articles. The present study will confirm or revise many of those data and then evaluate the systematic and evolutionary implications of the floral characteristics of Emblingia.

\section{Materials and methods}

Flowers of Emblingia calceoliflora F. Muell. in various stages of development were collected at Yardanogo Nature Reserve, north of Eneabba, Western Australia in early October, 2009 (voucher: Tobe 1338, KYO). They were fixed in FAA (five parts stock formalin, five parts glacial acetic acid, 90 parts $50 \%$ ethanol). To understand whether flowers change their orientation as they develop and how they change, an apical part of one shoot with small flower buds was serially and transversely sectioned (Fig. 2). The shoot was dehydrated through an ethanol series and then embedded in Technovit 7100 (Kulzer, Wertheim, Germany) for sectioning on a microtome. Likewise, flower buds in various stages of development were sectioned longitudinally or transversely to understand the development and positions of individual floral organs and to trace vascular supplies to them (Figs. 3, 4).

Serial resin sections cut at a thickness of 5-7 $\mu \mathrm{m}$ were stained with Heidenhain's hematoxylin and mounted in Entellan (Merck, Darmstadt, Germany). They were observed with an Olympus BX-51 microscope.

\section{Results}

General morphology of flower-bearing shoots and flowers

In native habitats of Western Australia, the flower-bearing shoots develop from the shade of the other tree to an open area (Fig. 1a, b). Each shoot has simple toothed leaves, which appear to be arranged horizontally in two rows. The leaves are, however, arranged decussately (for a transverse section of an apical part of a shoot see Fig. $2 \mathrm{~g}$ ). They are often erect, probably to avoid heated sandy soils or strong sunshine. The nodes are sometimes sub-opposite, because one of two opposite leaves moves slightly downward or 

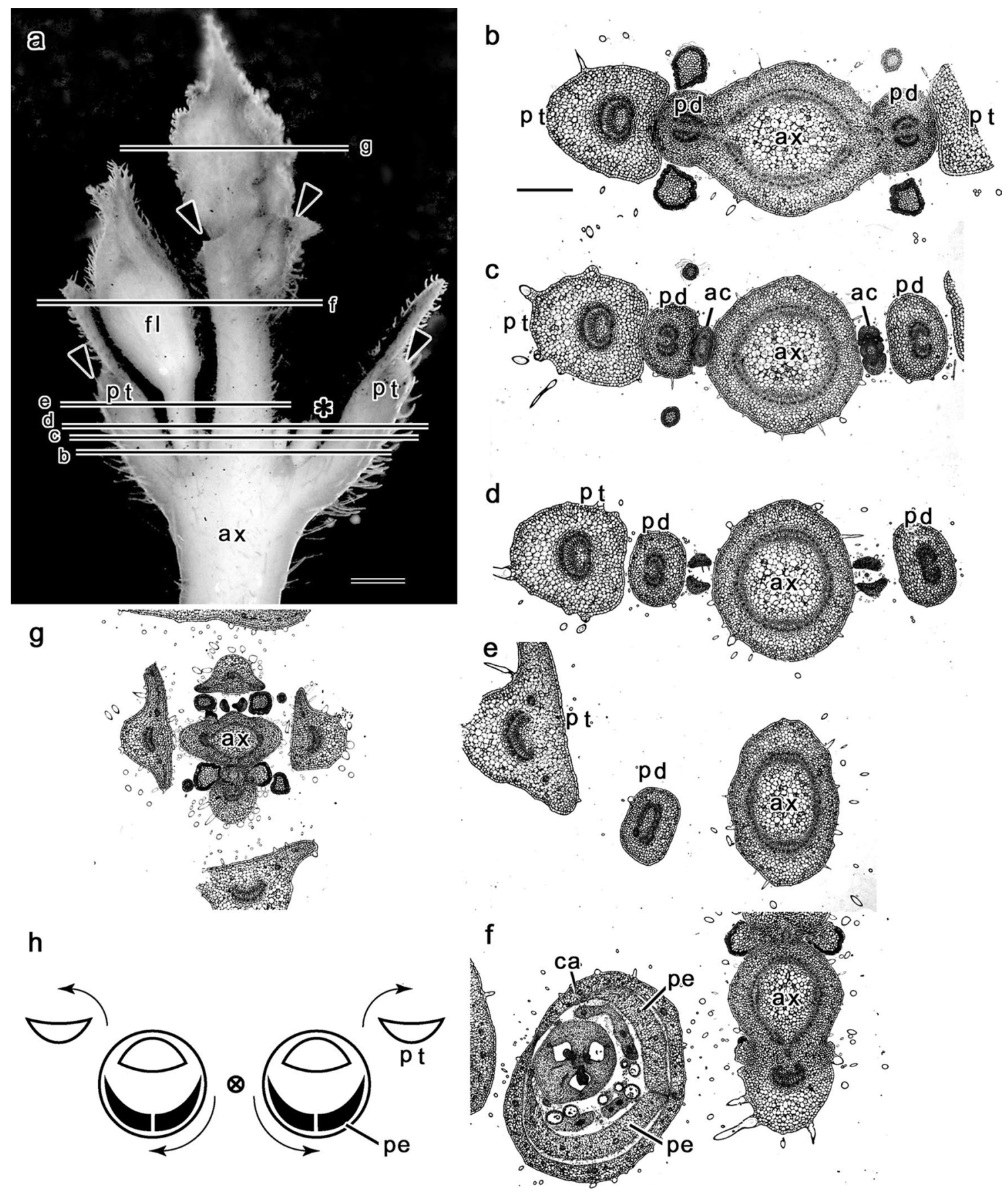

Fig. 2 Anatomy of a flower-bearing shoot of Emblingia calceoliflora. a Shoot examined, view from above. One flower bud (asterisk) and most parts of two flower-subtending leaves and four upper leaves (arrowheads) are removed. b-g Transverse sections of a flower-bearing shoot at levels marked $b-g$ in a, showing that a flower is borne from one of the axils of leaves arranged decussately, and that a cal-

ceolus (two petals) is positioned on the adaxial side. Note that the flower changes its orientation in the clockwise direction by turning the pedicel. h Diagram illustrating developmental changes of flower orientation. $a c$ accessory bud, $a x$ shoot axis, $f$ flower, $p d$ pedicel, $p e$, petal, pt petiole. Scale bars are $1 \mathrm{~mm}$ in a and $500 \mu \mathrm{m}$ in b. Scale bar in $\mathbf{b}$ also refers to $\mathbf{c}-\mathbf{g}$

upward. The flowers are solitary (Fig. 1b). Usually one or two pairs of flowers are found per shoot. The flowers are usually borne from opposite leaf axils, but either one of the two flowers is sometimes lacking or delayed in development. In fact, of the 30 flower-bearing, opposite leaf axils examined, 26 had flowers in both axils, and four had a flower bud in one of the two axils. In the former group of 26 flowers, one flower was larger than another in two cases. 
Fig. 3 Development of flowers in Emblingia calceoliflora. Longitudinal sections of flower buds and of an open flower, presented with the abaxial side above. a Flower bud with an ovule primordium in an ovary locule. b Flower bud with a developing ovule in an ovary locule. c Flower at anthesis. $a g$ androgynophore, $c a$ calyx, gy gynoecium, $l w$ longitudinal wall of petal, $n e$ nectary gland, $p e$ petal, st stamen, stm staminode. Scale bar is $500 \mu \mathrm{m}$ in $\mathbf{a}$, and refers to $\mathbf{b}, \mathbf{c}$
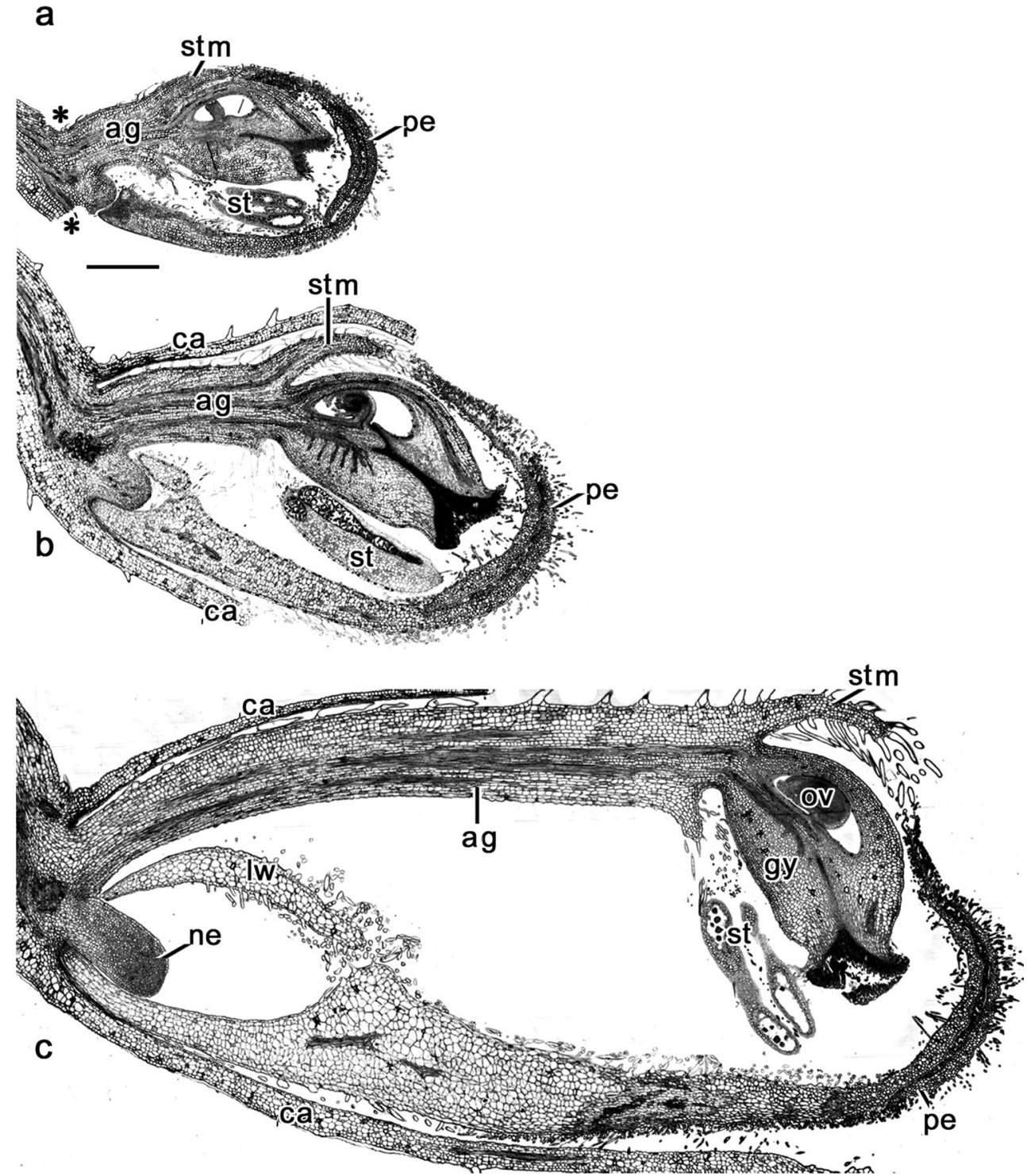

Flowers at anthesis are strongly monosymmetric with a calceolus (slipper-like corolla) comprising two petals always positioned downward (Fig. 1b, c). Each flower has a short pedicel approximately $4 \mathrm{~mm}$ long, which appears to turn variously (Fig. 1c). To determine the position of the calceolus in relation to the main axis, i.e., adaxial as in a floral diagram of Leins (Fig. 1d) or abaxial as in a floral diagram of Melville (Fig. 1e), and to understand how the pedicel turns as the flower develops, I examined an apical part of a shoot with small flower buds using serial transverse sections.

Anatomy of a shoot with flower buds

Figure 2a shows the lateral view of an apical part of a shoot with two opposite small flower buds. Judging from their sizes, the two flower buds appeared to be at the same developmental stages. One of them was removed for easier sectioning. In the other of the two flowers, the ovules were primordial in development (see Fig. 2f). Two opposite leaves, each subtending a flower bud, appeared to be positioned almost horizontally. A transverse section through a level slightly above the node, where the flower buds are borne, shows that the ventral sides of both the petiole of the flower-subtending leaf and the pedicel of the flower bud are oriented in an adaxial direction (Fig. 2b, c). The petiole has small stipules at the base, and an accessory bud is formed between the pedicel and the main axis (Fig. 2b-d). When pursued upwardly with microtome sections, the petiole and pedicel slightly turn anti-clockwise (upward) and clockwise (downward), respectively (Fig. 2d, e). The pedicel turns most strongly toward the clockwise direction at the highest level, i.e., just below the flower. Consequently, the leaf lamina is oriented upward, and the flower bud is oriented obliquely 
in relation to the main axis, with the two petals (calceolus) of the flower bud slightly downward (Fig. 2f). Observations of many flowers at anthesis showed that the pedicel turns more strongly to the clockwise or anti-clockwise direction than the pedicel of the flower bud we observed in Fig. 2a-g. Figure $2 \mathrm{~h}$ shows a diagram illustrating that the pedicel of a flower at anthesis turns $45^{\circ}$ in clockwise and anti-clockwise direction, and that the two petals (calceolus) are oriented downward as observed in the field.

\section{Development of flowers}

Besides the calceolus, another characteristic of Emblingia is the androgynophore (torus) bearing both the anthers and ovary/stigma on the top. Figure $3 \mathrm{a}-\mathrm{c}$ shows how the androgynophore develops when viewed from the lateral side. An analysis of its structure and development seems helpful to understand functional and evolutionary aspects.

Figure $3 \mathrm{a}$ shows a median longitudinal section of a flower bud, from which a calyx was removed for easier sectioning. This flower bud represents the youngest bud available, and shows that the androgynophore is very short. If we observed younger buds, their androgynophore would be much shorter or may not be recognized morphologically. As the flower develops, like both the calyx tube and calceolus, the androgynophore elongates, lifting the anthers and ovary/stigma close to the entrance of the flower (Fig. 3b). Anthers develop only on the adaxial side of the flower, and the ovary has a sessile stigma. At anthesis, both the anthers and ovary/stigma turn together inward with the anther tips and stigma oriented toward the inside of the flower (Fig. 3c).

During flower development, an extrastaminal nectary gland develops on the adaxial side from the bottom of the flower. It enlarges to be a short cylindrical structure with a height of about $0.8 \mathrm{~mm}$. Moreover, two short longitudinal walls develop around the nectary gland, each from the basal part of the two petals. These walls were recognized by Leins (Erdtman et al. 1969, p. 172) as "narrow ribbonlike appendages." At the time of anthesis, the two longitudinal walls, like a spur, envelop the nectary gland deep in the flower, probably accumulating nectar for pollinators (Figs. 3c, 4e-g). Flowers in Fig. 3a-c, like those in Fig. 1c, are presented with the adaxial side below, because the floral orientation in Fig. $3 \mathrm{c}$ is what pollinators would encounter in the field. The calceolus is presented downward, whereas the androgynophore is presented upward with a large tunnel-like space between them (Fig. 3c).

\section{Anatomy of flowers}

Vascular supply to individual floral organs, as well as the numbers and positions of the organs (sepals, petals,
Fig. 4 Anatomy of flowers of Emblingia calceoliflora. a Longitudinal section of flower bud, with the adaxial side above, obtained by sectioning through line $a$ in $\mathbf{e . ~} \mathbf{b}-\mathbf{h}$ Transverse sections of flower at levels marked $b-h$ in a, showing two petals and the nectary gland to be positioned on the abaxial side. All figures are presented with the adaxial side above. e1-h1 Magnified view of the transverse section of the flower enclosed by a rectangle in $\mathbf{e}-\mathbf{h}$, respectively. Note that five staminal traces are present in the basal region of the androgynophore. Arrow pairs in e1, g1, and h1 indicate bifurcation of each staminal trace to supply a stamen pair. $a g$ androgynophore, $a p$ appendage of petal, ca calyx, ne nectary, pe petal, pet petal trace, se sepal trace (or vascular strand in sepal), st stamen, stm staminode. Scale bars are $500 \mu \mathrm{m}$ in $\mathbf{a}, \mathbf{b}$ and $\mathbf{e}$, and $200 \mu \mathrm{m}$ in e1. Scale bar in $\mathbf{b}$ also applies to $\mathbf{c}$ and $\mathbf{d}$, scale bar in $\mathbf{e}$ to $\mathbf{f}-\mathbf{h}$, and scale bar in $\mathbf{e} \mathbf{1}$ to $\mathbf{f 1 - h 1}$. i-p Transverse sections of flower at levels marked $i-p$ in $\mathbf{a}$. i1, k1, and $\mathbf{m 1}$ Magnified view of the transverse section of the flower enclosed by a rectangle in $\mathbf{i}, \mathbf{k}$, and $\mathbf{m} . \mathbf{m} \mathbf{2}$ Magnified view of the transverse section of the flower enclosed by a rectangle in $\mathbf{m 1}$. Note the presence of staminodia and a tricarpellate structure of gynoecium. q Floral diagram. Arrows in i1 indicate traces to four fertile stamens, and arrowheads in $\mathbf{i} 1$ and $\mathbf{k} \mathbf{1}$ traces to five staminodes. $a g$ androgynophore, ca calyx, $c l$ calyx lobe, gy gynoecium, ov ovule, pe petal, st stamen, stm staminode. Scale bars are $500 \mu \mathrm{m}$ in $\mathbf{i}$ and $\mathbf{i 1}, 200 \mu \mathrm{m}$ in $\mathbf{m} \mathbf{2}$. Scale bar in $\mathbf{i}$ also applies to $\mathbf{j}-\mathbf{p}$, and scale bar in $\mathbf{i} \mathbf{1}$ to $\mathbf{k} \mathbf{1}$ and $\mathbf{m} \mathbf{1}$

stamens, and carpels constituting the gynoecium) were observed using anatomical sections. Figure $4 \mathrm{a}$ shows a median longitudinal section of a flower (see the line marked a in Fig. 4e), and Fig. 4b-p show its transverse sections through different levels marked b-p in Fig. 4a. All figures are presented with the adaxial side above. The pedicel, which is more or less transversely oblong in the transverse section, has a vascular cylinder in the center (Fig. 4b). When pursued upwardly from the pedicel to the flower base, the vascular cylinder emits five vascular bundles (Fig. 4c). Each is a sepal trace, which laterally divides into three to five strands in the sepal. Five sepals are connate for about half of their length as described by Leins in Erdtman et al. (1969), forming a calyx tube with five apical lobes. A median calyx-lobe or sepal is positioned on the adaxial side, with two sepals each on the latero-adaxial and lateroabaxial positions, respectively (Fig. 4p). At the basal level of the flower, the vascular cylinder further emits two vascular bundles. Each is a petal trace (Fig. 4d), while it remains as the vascular supply to the androgynophore. Two petals are present on the adaxial side. They alternate with three of the five calyx-lobes or sepals. As already described above, two short longitudinal walls develop, each from the basal region of a petal (Fig. $4 \mathrm{e}-\mathrm{g}$ ), enclosing a nectary gland like a spur. The nectary gland is depressed ovate in shape in the transverse section (Fig. 4e).

The androgynophore is transversely dilated, and its transverse section appears to have lateral wings on both sides (Fig. 4e-i). The vascular system in the androgynophore comprises vascular bundles supplied to the stamens and a gynoecium in the lower levels. The stamen bundles are located at the periphery, and the gynoecium bundles 
a
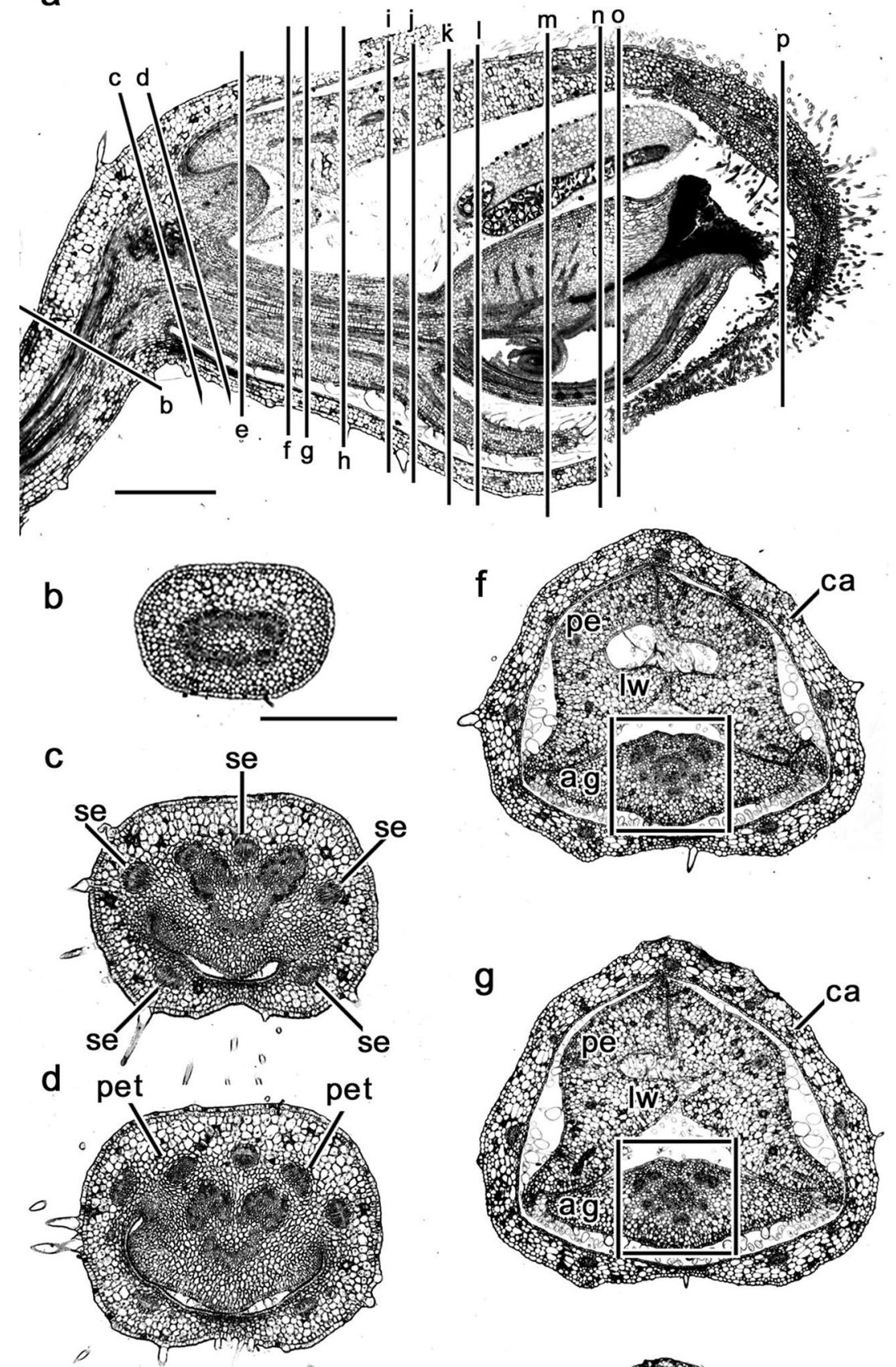

e10.
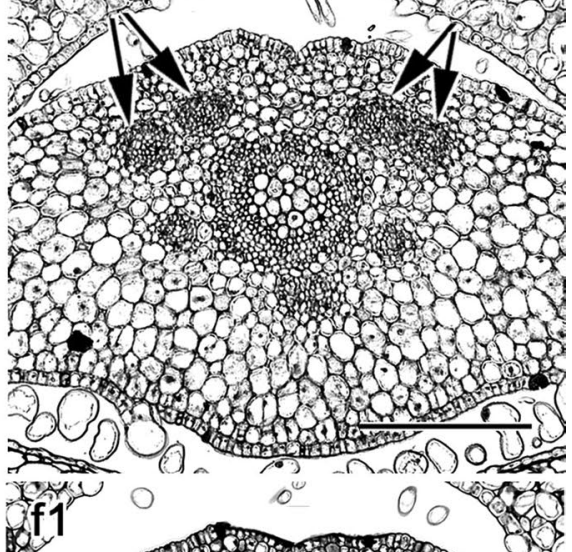
21 30101\%

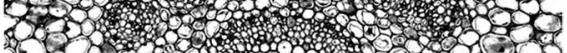

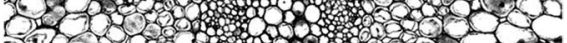
300 m

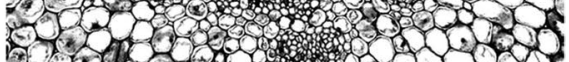
Y. 100100201 30 on

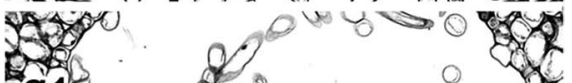
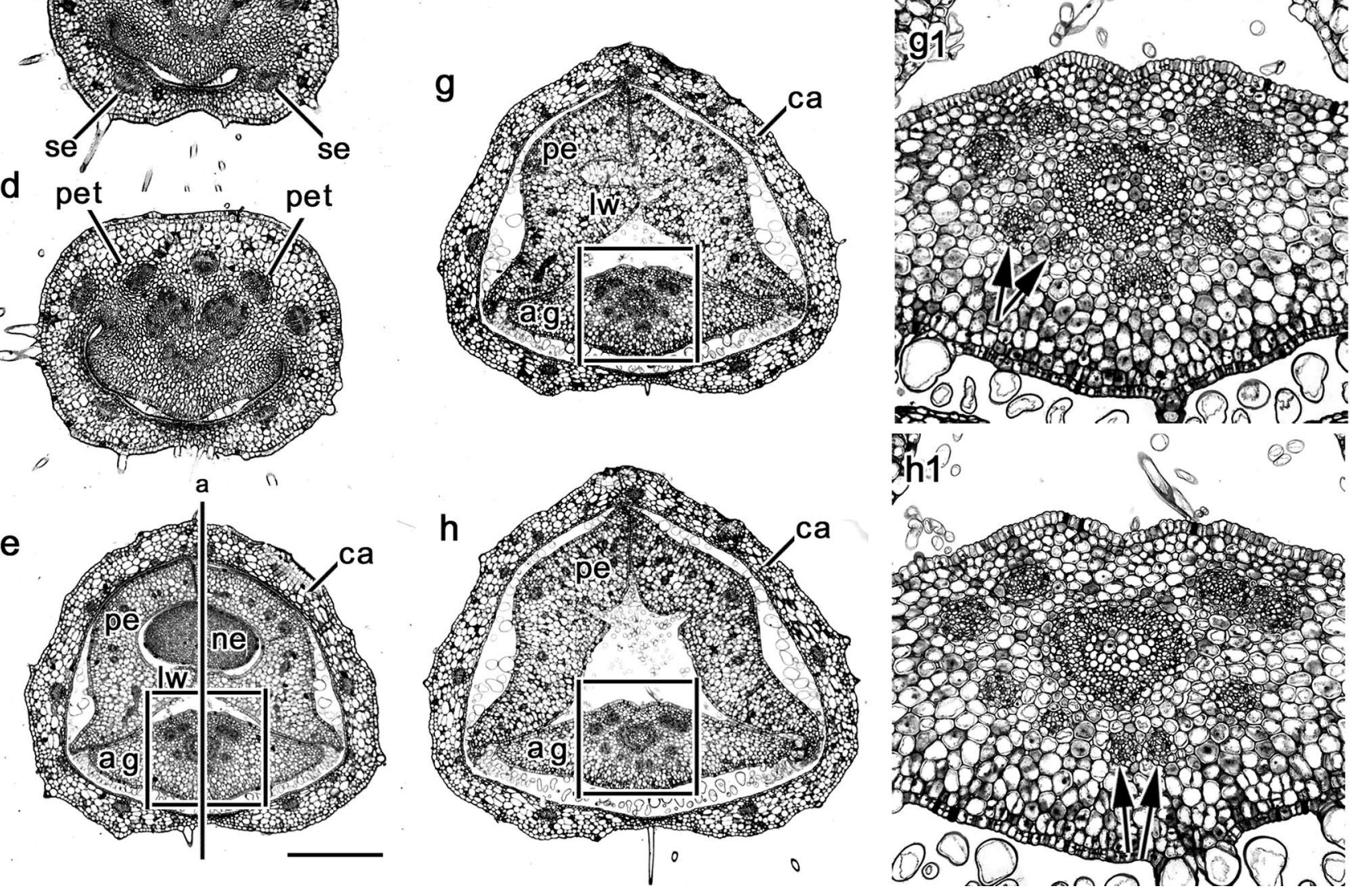

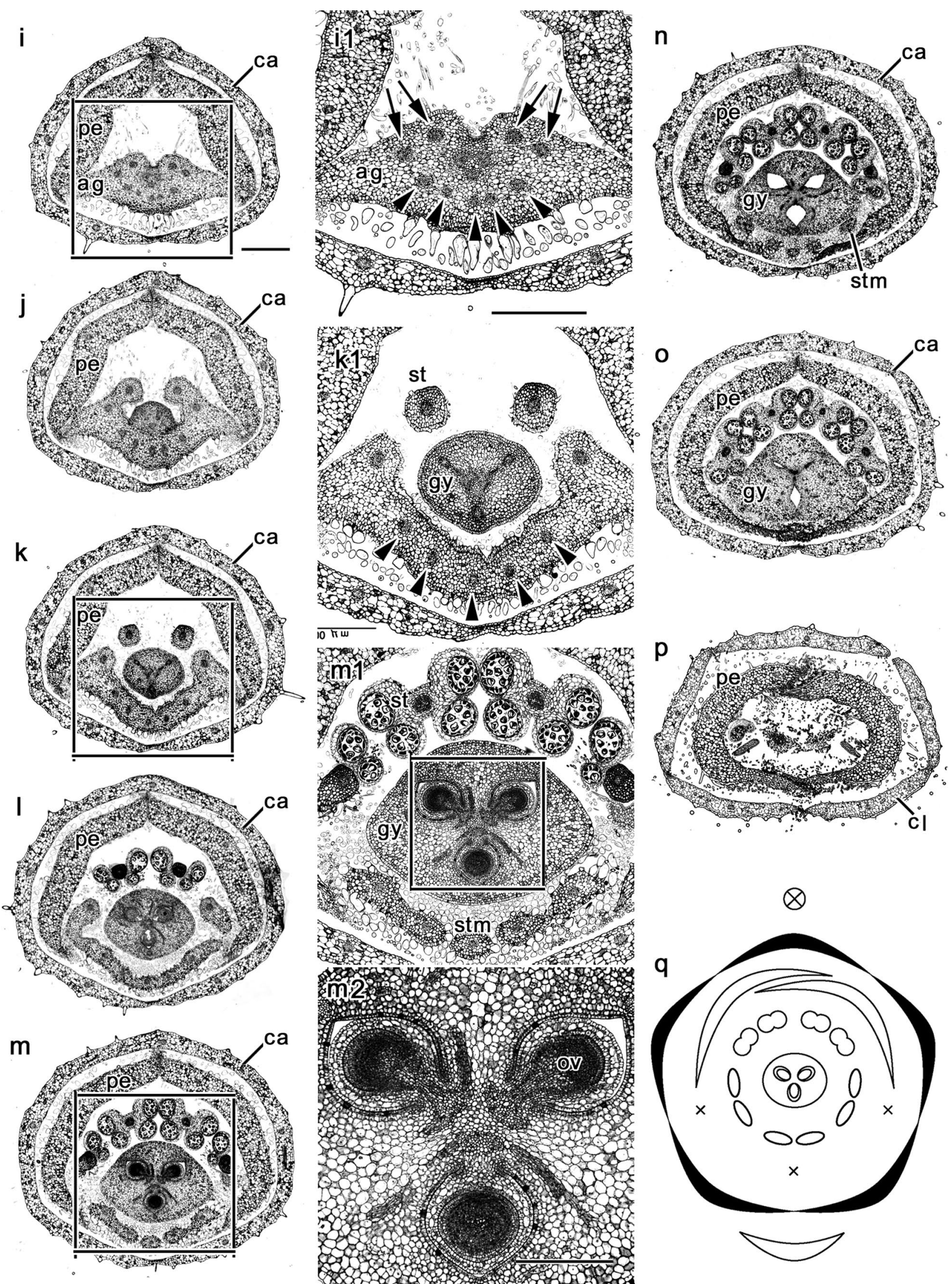

Fig. 4 continued 
in the center (Fig. 4e-h, e1-h1). There are five vascular bundles supplying the stamens at the lower level of the androgynophore. They alternate with five calyx-lobes or sepals, rather than with the two petals. Each of the five staminal traces bifurcates in upward direction. Bifurcation of two staminal traces on the latero-adaxial side results in a total of four vascular strands (Fig. 4e1). Likewise, two of the three staminal traces on the latero-abaxial and abaxial sides bifurcate, but one remains as it is without dividing (Fig. 4g1, h1). Consequently, nine vascular strands, four on the adaxial side and five on the abaxial side, are present in the upper level of the androgynophore (Fig. 4i, i1). The four strands on the adaxial side supply the four fertile stamens in the upper levels (Fig. 4f1-i1, k1, m1). Their filaments are short, less than $1 \mathrm{~mm}$ long in a flower at anthesis, with abundant unicellular hairs on the surface. In contrast, five strands on the abaxial side supply five small leafy organs, respectively, in the upper levels (Fig. $4 \mathrm{j}-\mathrm{n}, \mathrm{k} 1, \mathrm{~m} 1$ ). The leafy organs represent staminodia (sterile stamens) and are more or less connate at the base, forming the so-called "hood" on the opposite side of the four fertile stamens (Fig. 4l-n, m1). Observations of a few other flowers indicate that the number of staminodia vary from three to six. Melville (Erdtman et al. 1969, p. 176) also observed a variation from three to five staminodia ("lobes"). In the case of the six staminodia, all of the three staminal traces must bifurcate to supply them.

The vascular system in the center of the androgynophore consists of three vascular bundles at the lower level of the gynoecium (Fig. 4i1). In upward direction each diverges into three strands, i.e., one dorsal carpellary bundle and two ventral carpellary bundles (Fig. 4k1). The gynoecium is trilocular (Fig. 4m1, m2), and comprises three carpels. Each locule is uniovulate, and placentation is axile (Fig. $4 \mathrm{~m} 1$, $\mathrm{m} 2)$. Ovular supply is given by fused ventrals lying opposite the locule (Fig. $4 \mathrm{~m} 2$ ). In the upper levels of the flower bud examined, the calyx is divided into five valvate lobes, whereas the petals are valvate in the lower level but imbricate in the upper level (Fig. 4o, p).

Figure $4 \mathrm{q}$ demonstrates a floral diagram of Emblingia calceoliflora, which was obtained by anatomical observations.

\section{Discussion}

Is the flower resupinate or not?

The answer to this question is neither "yes" nor "no," though flowers change their orientation during their development. As we observed using anatomical sections of an apical part of a flower-bearing shoot, the pedicel of a developing flower bud turns to a varying degree, in clockwise or anti-clockwise direction, according to the position of the leaf axils producing flower buds in relation to the ground surface. If the flower bud is borne from a leaf axil that is positioned horizontally, the pedicel turns $45^{\circ}$ clockwise or anticlockwise (Fig. 2h). As a result, the flower is always positioned with its calceolus downward.

Why do the flowers of Emblingia change their orientation during their development? It is obviously associated with insect-pollination. By changing their orientation, the flowers have the anthers and ovary/stigma upward, the calceolus downward, and the nectary gland downward and deep inside. A combination of the anthers and stigma on the top of androgynophore is similar to the gynostemium in orchid flowers. Both the anthers and ovary/stigma are oriented inside the flower at anthesis (Fig. 3c). Because the flowers have fertile stamens only on the adaxial side with the staminodia (hood) on the abaxial side, they have the anthers posterior to the stigma (Fig. 3c). In addition, a large space like a tunnel develops between the androgynophore and calceolus (petals) of the flower. Although I did not see any insects on the plant in the field during the few hours in the morning of October 2009, it is possible that some insects had entered and exited the flowers after sucking nectar in the spur-like container deep in the flower. These insects probably crawled on or flew over the ground surface early in the morning or late in the evening because it is too hot in the daytime. When entering the flower, an insect provides the stigma with pollen grains from other flowers, and when leaving the flower, the insect gets pollen grains on its head or back from the anthers. The calceolus probably functions as a landing platform for insects.

Answers to the questions pertaining to the petals, stamens, nectary, hood, and carpels

Anatomical observations confirmed that two distinct petals which are placed downward at anthesis form the calceolus on the adaxial side. The two petals alternate with three of the five calyx-lobes or sepals, indicating that five petals existed originally; two of them developed into the calceolus and the remaining three became extinct. Melville in Erdtman et al. (1969, p. 178) assumed that "the hood represents a third petal which has become fused to the androgynophore in the course of evolution." However, this is not likely because anatomical evidence shows that the hood is a morphologically complex structure comprising three to six connate staminodia (or sterile stamens), not representing a petal.

As for the questions of how many stamens originally existed and how many whorls of stamens are present in a flower, anatomical observations indicate that originally five stamens were present in a single whorl. As stated in the Introduction, Leins considered that ten stamens were 
originally present in two whorls of five stamens, whereas Melville assumed that five stamens originally existed in a flower. According to Melville's interpretation, two lateroabaxial stamens are fertile, each dividing into two; two latero-adaxial stamens were lost and the abaxial stamen developed into a nectary gland. An anatomical examination of microtome sections revealed that five staminal traces are present in the lower levels of the androgynophore, indicating that the original number of stamens is five, and that they alternate with the calyx-lobes or sepals, rather than with the petals. The flowers of Emblingia are thus obhaplostemonous with double positions of the stamens and staminodia. Two of the five original stamens are fertile, and the three others sterile and staminodial. The vascular anatomy shows that every staminal trace upwardly bifurcates to supply two stamens on the same whorl, providing evidence for the occurrence of stamen dédoublement. Mueller (1860-1861) and later authors always found four fertile stamens. Dédoublement, however, does not necessarily occur in all of the three sterile stamens. If it does not occur in one or two of the three sterile stamens, the flowers have four or five staminodes instead of six, as Melville observed as four or five "lobes" (Erdtman et al. 1969, p. 176). Melville interpreted one of the five stamens as having developed into a nectary gland, but this is incorrect. The nectary gland is positioned outside of the stamen whorl.

Finally, as for the number of carpels constituting a gynoecium, anatomical observations showed that the gynoecium is always three-loculed and formed by three carpels. Based on the 19 flowers that I examined anatomically, there were neither unicarpellate and unilocular gynoecium, as Melchior (1964) and Watson and Dallwitz (1992 onwards) describe, nor bicarpellate gynoecia. A single ovule is borne from an axial placentation in each locule, and the ovule never has a basal position in the locule as described by Takhtajan $(1997,2009)$ and Stevens (2001 onwards).

A summary of the floral morphology and structure of Emblingia

Prior to my analyses, information on floral morphology and structure of Emblingia calceoliflora has been controversial. As discussed above, anatomical and developmental analyses using fresh material have answered the questions stated in the Introduction and have updated some characters. The floral morphology and structure of E. calceoliflora can be summarized as follows.

Flowers solitary with a pedicel of about $4 \mathrm{~mm}$ long, pentamerous, and strongly monosymmetric. Calyx comprising five sepals, one median adaxial, two latero-adaxial, and two latero-abaxial. Sepals connate; a calyx tube apically dividing into five lobes, with a deep slit on the abaxial side in association with strong monosymmetry. Corolla comprising two latero-adaxial petals that alternate with three sepals on the adaxial and latero-adaxial side, developing into a large slipper-like form (calceolus) on the adaxial side. Two petals distinct throughout their length, basally valvate and apically imbricate. Two short longitudinal walls, both from the basal region of the petal, developing to form a spur-like container to enclose a swollen nectary gland. The nectary gland extrastaminal, adaxial, forming between the two petals.

Androecium originally comprising five stamens in a single whorl, which alternate with calyx-lobes or sepals and opposite the petals; thus, flowers obhaplostemonous. As shown in vascular anatomy, lateral dédoublement occurring in five original stamens, resulting in four fertile stamens on the adaxial side and (three to) six staminodia on the abaxial side. Fertile stamens bearing anthers above a short filament; staminodia lacking anthers, connate at the base to form the "hood." Gynoecium tricarpellate, trilocular with a single ovule on axial placentation in each locule. Androgynophore long, with a combination of anthers and ovary/stigma like a gynostemium on the top. Both anthers and ovary/stigma turning inside into the flower at anthesis.

During flower development, a pedicel turning clockwise or anti-clockwise to various degrees according to flowerbud position, placing the calceolus downward and androgynophore upward in flowers at anthesis. Flowers at anthesis with a large space between the calceolus and the androgynophore and a nectary gland deep within it.

\section{Comparisons with other families of the Brassicales}

An understanding of the exact floral morphology and structure of Emblingia enables a comparison with flowers of the 17 other families of Brassicales. I reviewed as many characters of floral morphology and structure for the other families as possible using published data: Akaniaceae (Ronse de Craene et al. 2002), Bataceae (Ronse de Craene 2005), Capparaceae (Ronse de Craene and Smets 1997), Caricaceae (Ronse de Craene and Smets 1999), Gyrostemonaceae (Hufford 1996), Moringaceae (Olson 2003; Ronse de Craene et al. 1998), Pentadiplandraceae (Ronse de Craene 2002), Salvadoraceae (Ronse de Craene and Wanntorp 2009), Setchellanthaceae (Tobe et al. 1999), Tropaeolaceae (Ronse de Craene and Smets 2001). Thus all 17 families except for the poorly known Borthwickiaceae were considered (Ronse de Craene and Haston 2006). Ronse de Craene and Haston (2006) analyzed 42 characters relating to floral morphology, development and structure for cladistic analysis of Brassicales in their combined morphology-molecular study. Among these characters, six related to early floral development had no information for Emblingia. Although those six characters were also not resolved with the present 


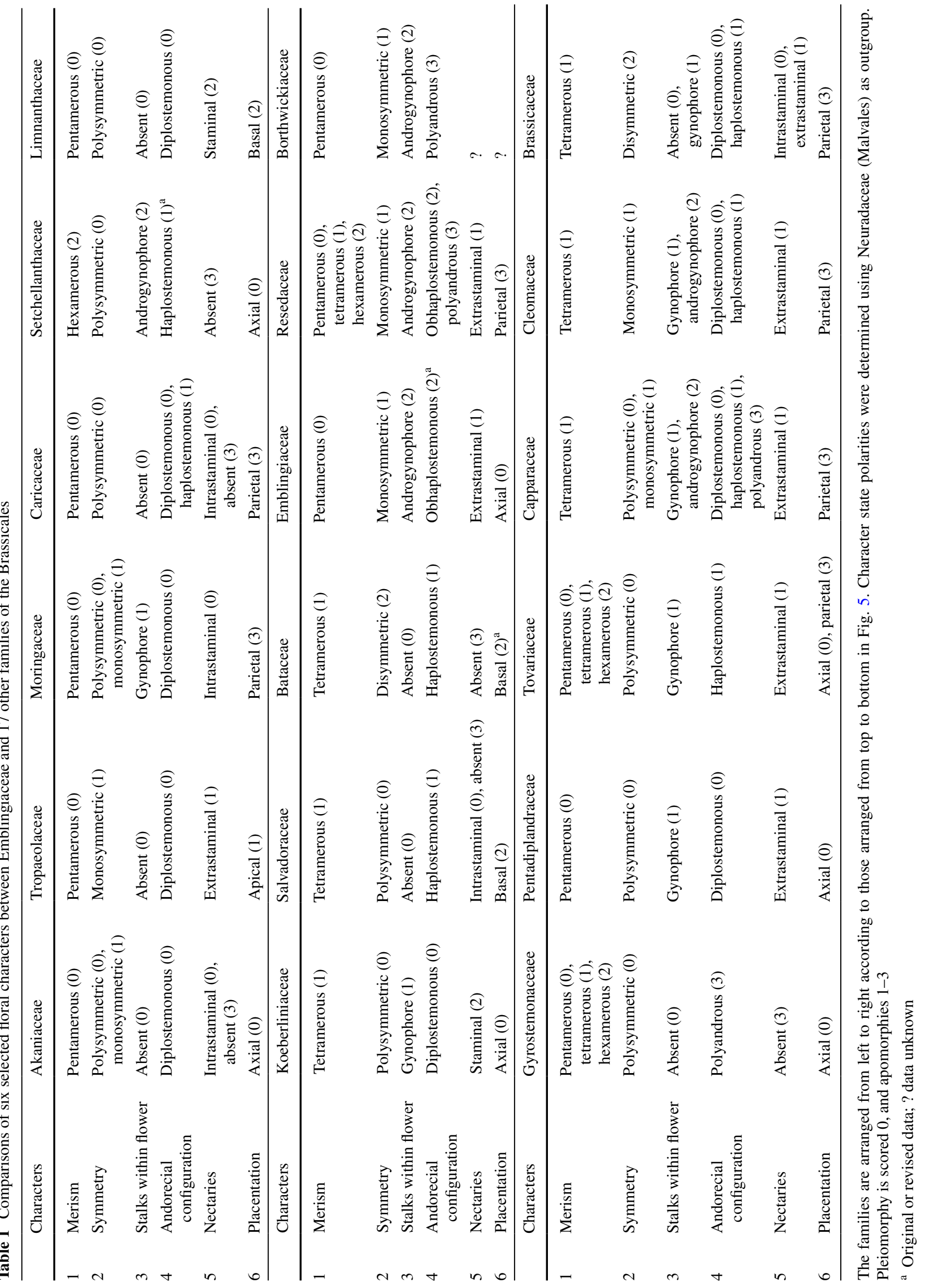




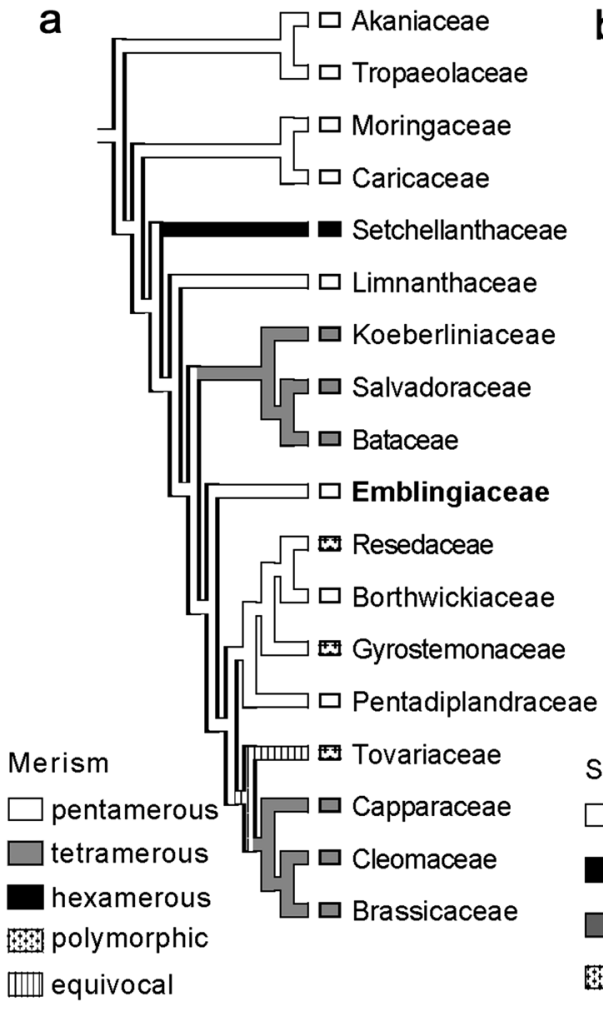

b

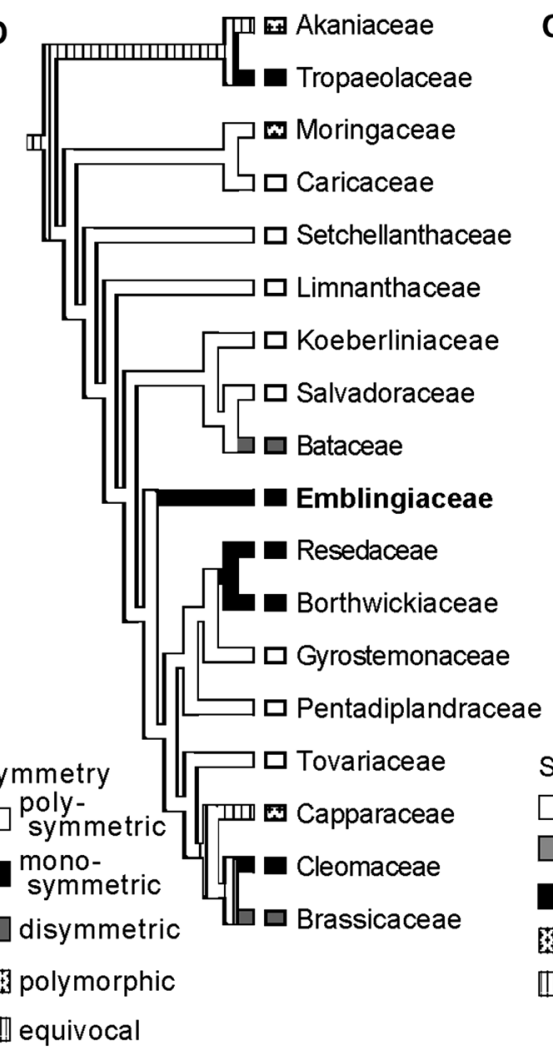

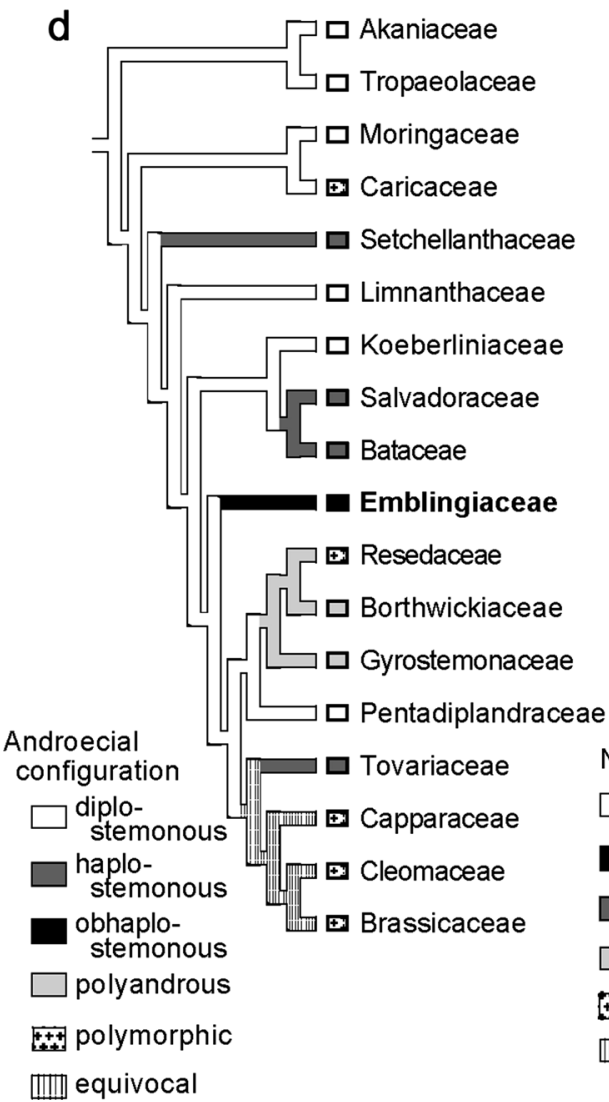

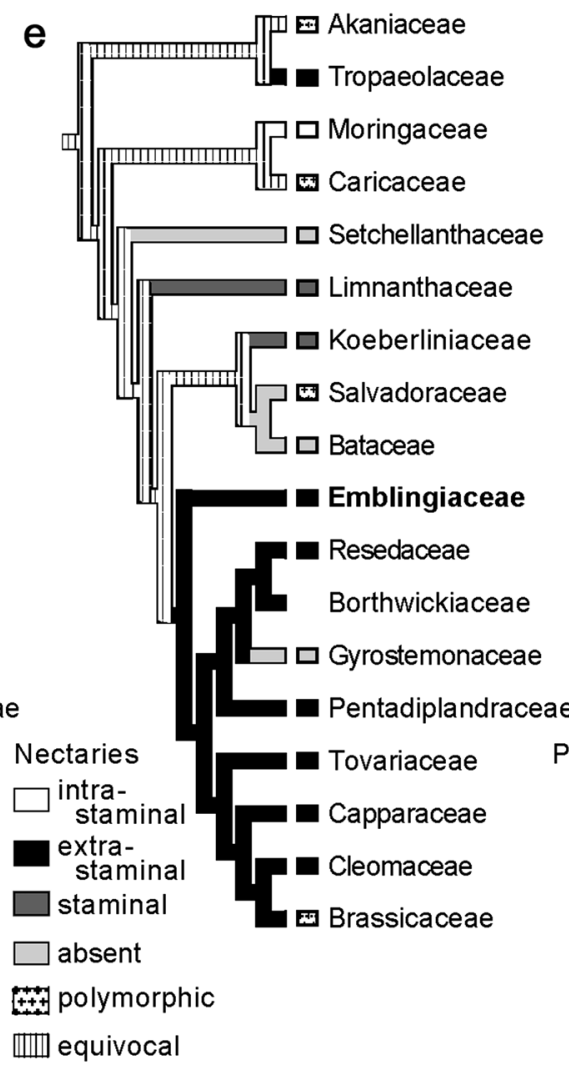

血 equivocal
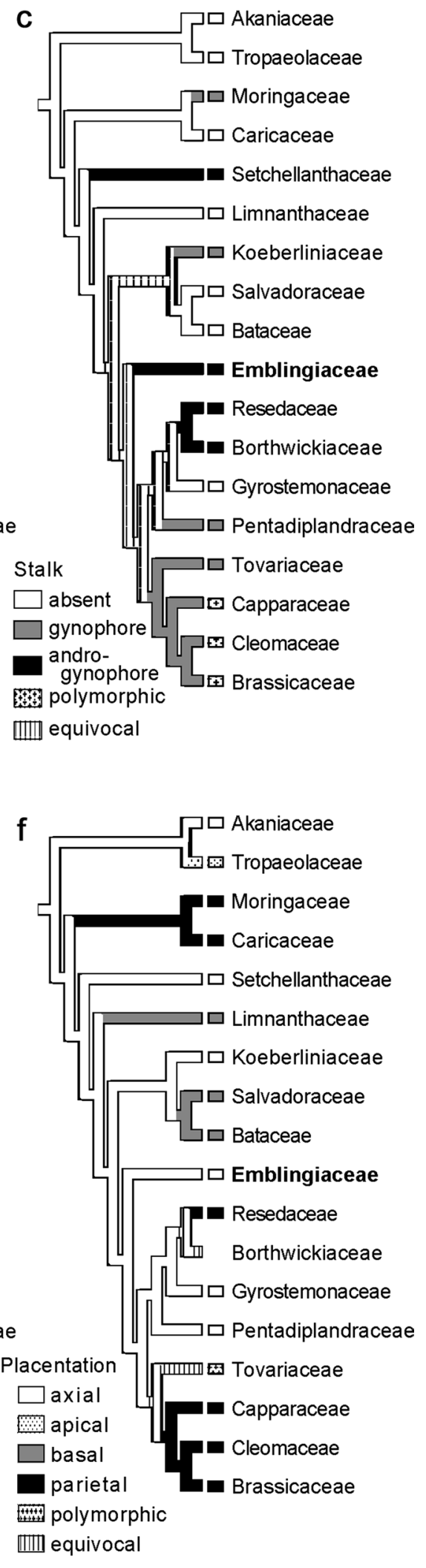
4 Fig. 5 Distribution $(\mathbf{a}-\mathbf{f})$ of the character states of six characters (1-6 in Table 1) on a phylogenetic tree of the Brassicales. The tree is modified from Hall et al. (2004) and Su et al. (2012). Note that an extrastaminal nectary is a synapomorphy of the core Brassicales (including Emblingiaceae)

study, data for the following six characters for Emblingia were revised. Flowers are monosymmetric (not polysymmetric) at maturity; androecial configuration is obhaplostemonous (not diplostemonous); staminodia occur in the same whorl as stamens (not in two whorls); reduction of stamen number within a whorl is absent; filaments are hairy (not glabrous); and the number of carpels is three (not three and two).

Based on all the available data, I mapped character states of more than 36 characters on a phylogenetic tree of the Brassicales using MacClade version 3.04 (Maddison and Maddison 2005). The tree was modified from Hall et al. (2004) and Su et al. (2012), placing Emblingiaceae as sister to the rest of the core Brassicales. Polarities of their respective character states were determined using the Neuradaceae, basalmost in the Malvales (Soltis et al. 2000), as an outgroup of the Brassicales, following a previous paper on Koeberliniaceae (Tobe and Raven 2008). Data on the Neuradaceae were obtained from Murbeck (1916), Ronse de Craene and Smets (1995), and unpublished data (Tobe, personal observation). In general the flowers are greatly diversified in the Brassicales, and homoplasies are frequent in many characters. Ultimately I selected six characters that are likely to represent floral evolution and diversity in Brassicales. Some of them have often been used to distinguish one group of families from another in the Brassicales (Ronse de Craene 2010). The characters are as follows: merism, symmetry, the presence or absence of a stalk supporting an ovary, position of nectaries, and placentation. The six characters (1-6) and their respective character states are presented in Table 1.

Figure $5 \mathrm{a}-\mathrm{f}$ shows the distribution of character states of the six characters. While the flowers of Emblingia retain plesiomophies such as pentamery and axial placentation (Fig. 5a, f), they have apomorphies such as monosymmetry, androgynophore, obhaplostemony, and an extrastaminal nectary (Fig. 5b-e). Among the apomorphies, obhaplostemony is restricted to Emblingia, whereas monosymmetry and androgynophore are homoplasies that occur in a clade of Borthwickiaceae and Resedaceae. Monosymmetry is also found in Tropaeolaceae and Capparaceae pro parte, and androgynophore is also found in Setchellanthaceae. Only the extrastaminal nectary is a synapomorphy of Emblingiaceae and the rest of the core Brassicales [Borthwickiaceae (data uncertain), Brassicaceae, Capparaceae, Cleomaceae, Gyrostemonaceae Pentadiplandraceae, Resedaceae, and Tovariaceae], although it occurs as a homoplasy in Tropaeolaceae. Within the core Brassicales, the nectary is lost in Gyrostemonaceae (with anemophilous flowers).

Apart from the six characters discussed above, the presence of paired stamens is one of the noticeable features of Emblingia. The vascular anatomy of the androgynophore shows that the paired stamens receive their respective traces by bifurcation from a single stamen trace, providing evidence for the occurrence of stamen dédoublement. Such paired stamens are known in some other Brassicales, particularly in the core Brassicales. The flowers of Brassicaceae, Capparaceae, and Cleomaceae nearly always have two outer stamens and four inner stamens (Ronse de Craene 2010). Two pairs of the inner stamens have often been interpreted as a result of dédoublement, although this interpretation is doubted by Ronse de Craene and Smets (1993; references cited therein). I have reported that stamen chorisis (i.e., the splitting of a stamen into more than one) occurs in Setchellanthus (Setchellanthaceae) of the non-core Brassicales (Tobe et al. 1999). In Setchellanthus a total of 40-70 stamens comprise six fascicles, each having been derived by stamen chorisis. Borthwickiaceae (Borthwickia trifoliata W.W. Smith only), a new monotypic, core-brassicalean family recently proposed, has 60-70 stamens in a flower (Su et al. 2012). Some species of Capparaceae such as Boscia senegalensis Lam., Capparis cynophallophora L., C. micracantha DC., and Colicodendron yco (Mart.) Mart. ("Capparis yco") are known to have as many as 40 stamens that are centrifugally initiated (Ronse de Craene and Smets 1997; Ronse de Craene 2010). Those stamens might have been derived by stamen chorisis as in Setchellanthus. To the best of my knowledge, the centrifugal stamen initiation is closely associated with stamen chorisis as in Glaucidium (Ranunculaceae) (Tamura 1972), Harungana (Hypericaceae) (Ronse de Craene and Smets 1991), and Paeonia (Paeoniaceae) (Hiepko 1964, 1966; Sawada 1971). The occurrence of dédoublement in Emblingia suggests that stamen splitting (chorisis and dédoublement) might be a generalized feature in the Brassicales, at least in the core Brassicales.

Overall, the flowers of Emblingia have a distinctive combination of plesiomorphies and apomorphies [synapomorphies (including homoplasies) and autapomorphies). Based on the available information, the extrastaminal nectary is the only synapomorphy supporting the core-Brassicales including Emblingiaceae, although it is uncertain in Borthwickiaceae. More strictly, however, the nectary gland of Emblingia differs from those in the other core-brassicalean families because it is enclosed by the spur-like container developed from petals in the bottom of the flower. Many of the floral features of Emblingia represent a unique syndrome of insect pollination. Emblingia seems to have survived in close association with the pollinators adapted to the particularly dry habitat of Western Australia. 
Acknowledgments I am grateful to Juliet Wege and Allan Tinker for their assistance in collecting the materials used in the present study and to Tomoki Kadokawa for his assistance in preparing some figures used in the present article. The study was supported by a Grant-in-Aid for Scientific Research from the Japan Society for the Promotion of Science (No. 25440208).

\section{References}

Airy Shaw HK (1965) Diagnoses of new families, new names, etc., for the seventh edition of Willis's Dictionary. Kew Bull 18:249-273

Ao C, Tobe H (2015) Floral morphology and embryology of Helwingia (Helwingiaceae, Aquifoliales): systematic and evolutionary implications. J Plant Res 128:161-175

APG (Angiosperm Phylogeny Group) (1998) An ordinal classification of the families of flowering plants. Ann Missouri Bot Gard 85:531-553

APGII (Angiosperm Phylogeny Group II) (2003) An update of the Angiosperm Phylogeny Group classification for the orders and families of flowering plants: APG II. Bot J Linn Soc 141:399-436

APGIII (Angiosperm Phylogeny Group III) (2009) An update of the Angiosperm Phylogeny Group classification for the orders and families of flowering plants: APG III. Bot J Linn Soc 161:105-121

Bentham G, Hooker JD (1862-1867) Capparideae. Genera Plantarum, vol 1. Reeve Co., London, pp 968-969

Chandler GT, Bayer RJ (2000) Phylogenetic placement of the enigmatic Western Australian genus Emblingia based on $r b c L$ sequences. Plant Species Biol 15:67-72

Cronquist S (1981) An integrated system of classification of flowering plants. Columbia University Press, New York

Dahlgren R (1980) A revised system of classification of the angiosperms. Bot J Linn Soc 80:91-124

Diels L, Pritzel E (1905) Fragmenta Phytographiae Australiae occidentalis. Beiträge zur Kenntnis der Pflanzen Westaustraliens, ihrer Verbreitung und ihrer Lebens-Verhältnisse. Bot Jahrb Syst 35:55-662

Erdtman G, Leins P, Melville R, Metcalfe CR (1969) On the relationships of Emblingia. Bot J Linn Soc 62:169-186

Hall JC, Iltis HH, Sytsma KJ (2004) Molecular phylogenetics of core Brassicales, placement of orphan genera Emblingia, Forchhammeria, Tirania, and character evolution. Syst Bot 29:654-669

Hiepko P (1964) Das zentrifugale Androeceum der Paeoniaceae. Ber Deutsch Bot Ges 77:427-435

Hiepko P (1966) Zur Morphologie, Anatomie und Funktion des Diskus der Paeoniaceae. Ber Deutsch Bot Ges 79:233-245

Hufford L (1996) Developmental morphology of female flowers of Gyrostemon and Tersonia and floral evlution among Gyrostemonaceae. Am J Bot 83:1471-1487

Maddison DR, Maddison WP (2005) MacClade, version 4.08. Sinauer, Sunderland

Melchior H (1964) Papaverales. In: Melchior H (ed) A Engler's Syllabus der Pflanzenfamilien. II. ed. 12. Gebrüder Borntraeger, Berlin, pp 178-192

Mueller E (1860-1861) Fragmenta Phytographiae Australiae, Capparideae, vol 12. Cubern, Coloniae, Victoria, pp 2-4

Murbeck SV (1916) Über die Organisation, Biologie und verwandtschaftlichen Beziehungen der Neuradaceen. Lund Univ Arrskr 12:1-29

Olson ME (2003) Ontogenetic origins of floral bilateral symmetry in Moringaceae (Brassicales). Am J Bot 90:49-71

Pax F, Hoffmann K (1936) Capparidaceae. In: Engler A, Prantl K (eds) Die natürlichen Pflanzenfamilien, vol 17b. Wilhelm Engelmann, Leipzig, pp 146-223
Ronse de Craene LP (2002) Floral development and anatomy of Pentadiplandra (Pentadiplandraceae): a key genus in the identification of floral morphological trends in the core Brassicales. Can J Bot 80:443-459

Ronse de Craene LP (2005) Floral developmental evidence for the systematic position of Batis (Bataceae). Am J Bot 92:752-760

Ronse De Craene LP (2010) Floral diagrams. An aid to understanding flower morphology and evolution. Cambridge University Press, Cambridge

Ronse de Craene LP, Haston E (2006) The systematic relationships of glucosinolate-producing plants abd related families: a cladistic investigation based on morphological and molecular characters. Bot J Linn Soc 151:453-494

Ronse de Craene LP, Smets EF (1991) Androecium and floral nectaries of Harungana madagascariensis (Clusiaceae). Plant Syst Evol 178:179-194

Ronse de Craene LP, Smets EF (1993) Dédoublement revisited: towards a renewed interpretation of the androecium of the Magnoliophytina. Bot J Linn Soc 113:103-124

Ronse de Craene LP, Smets EF (1995) The floral development of $\mathrm{Neu}$ rada procumbens L. (Neuradaceae). Acta Bot Neerl 44:439-451

Ronse de Craene LP, Smets EF (1997) A floral ontogenetic study of some species of Capparis and Boscia, with special emphasis on the androecium. Bot Jahrb Syst 119:231-255

Ronse de Craene LP, Smets EF (1999) The floral development and anatomy of Carica papaya (Caricaceae). Can J Bot 77:582-598

Ronse de Craene LP, Smets EF (2001) Floral developmental evidence for the systematic relationships of Tropaeolum (Tropaeolaceae). Ann Bot 88:879-892

Ronse de Craene LP, Wanntorp L (2009) Floral development and anatomy of Salvadoraceae. Ann Bot 104:913-923

Ronse de Craene LP, de Laet J, Smets EF (1998) Floral development and anatomy of Moringa oleifera (Moringaceae): what is the evidence for a capparalean or sapindalean affinity? Ann Bot 82:273-284

Ronse de Craene LP, Yang TYA, Schols P, Smets EF (2002) Floral anatomy and systematics of Bretschneidera (Bretschneideraceae). Bot J Linn Soc 139:29-45

Sawada M (1971) Floral vascularization of Paeonia japonica with some consideration on systematic position of the Paeoniaceae. Bot Mag (Tokyo) 84:51-60

Soltis DE, Soltis PS, Chase MW, Mort ME, Albach DC, Zanis M, Savolainen V, Hahn WH, Hoot SB, Fay MF, Axtell M, Swensen SM, Prince LM, Kress WJ, Nixon KC, Farris JS (2000) Angiosperm phylogeny inferred from $18 \mathrm{~S}$ rDNA, $r b c L$, and $a t p B$ sequences. Bot J Linn Soc 133:381-461

Stevens P (2001 onwards) Angiosperm phylogeny website. http:// www.mobot.org/MOBOT/research/APweb/ Accessed 10 Nov 2014 (website version 13)

Su J-X, Wang W, Zhang L-B, Chen Z-D (2012) Phylogenetic placement of two enigmatic genera, Borthwickia and Stixis, based on molecular and pollen data, and the description of a new family of Brassicales, Borthwickiaceae. Taxon 61:601-611

Takhtajan A (1980) Outline of the classification of flowering plants Magnoliophyta. Bot Rev 46:225-359

Takhtajan A (1997) Diversity and classification of flowering plants. Columbia University Press, New York

Takhtajan A (ed) (2009) Flowering plants, 2nd edn. Springer, Netherlands

Tamura M (1972) Morphology and phyletic relationships of the Glaucidiaceae. Bot Mag (Tokyo) 85:29-41

Thorne RF (1992) Classification and geography of the flowering plants. Bot Rev 58:225-348

Tobe H (2012) Floral structure of Cardiopteris (Cardiopteridaceae) with special emphasis on the gynoecium: systematic and evolutionary implications. J Plant Res 125:361-369

Tobe H (2013) Floral anatomy and structure of Phyllonoma (Phyllonomaceae): systematic and evolutionary implications. J Plant Res 126:709-718 
Tobe H, Raven PH (2008) Embryology of Koeberlinia (Koeberliniaceae): evidence for core brassicalean affinities. Am J Bot 95:1475-1486

Tobe H, Carlquist S, Iltis HH (1999) Reproductive anatomy and relationships of Setchellanthus caeruleus (Setchellanthaceae). Taxon 48:277-283
Watson L, Dallwitz MJ (1992 onwards) The families of flowering plants: descriptions, illustrations, identification, and information retrieval. Version: 19 August 2014. http://delta-intkey.com. Accessed 2 Feb 2015 